\title{
EUROPEAN CONSENSUS-BASED RECOMMENDATIONS FOR THE DIAGNOSIS AND TREATMENT OF RARE PAEDIATRIC VASCULITIDES - THE SHARE INITIATIVE
}

${ }^{*}$ Nienke de Graeff ${ }^{1},{ }^{*}$ Noortje Groot ${ }^{1,2,3}$, Paul Brogan ${ }^{4}$, Seza Ozen ${ }^{5}$, Tadej Avcin ${ }^{6}$, Brigitte BaderMeunier $^{7}$, Pavla Dolezalova ${ }^{8}$, Brian M Feldman ${ }^{9}$, Isabelle Kone-Paut ${ }^{10}$, Pekka Lahdenne ${ }^{11}$, Stephen D Marks ${ }^{4}$, Liza McCann³, Clarissa Pilkington ${ }^{4}$, Angelo Ravelli2, Annet van Royen ${ }^{1}$, Yosef Uziel'13, Bas Vastert ${ }^{1}$, Nico Wulffraat ${ }^{1}$, Sylvia Kamphuis ${ }^{2}$, Michael W Beresford ${ }^{3,14}$

${ }^{1}$ Wilhelmina Children's Hospital, Utrecht, The Netherlands; ${ }^{2}$ Sophia Children's Hospital, Erasmus Medical Centre, Rotterdam, The Netherlands; ${ }^{3}$ Department of Paediatric Rheumatology, Alder Hey Children's Hospital, Liverpool, United Kingdom; ${ }^{4}$ University College London Great Ormond Street Institute of Child Health and Great Ormond St Hospital for Children NHS Foundation Trust, London, United Kingdom; ${ }^{5}$ Dept. of Paediatric Rheumatology, Hacettepe University, Ankara, Turkey; 6 University Children's Hospital Ljubljana, Ljubljana, Slovenia; ${ }^{7}$ Necker Hospital, Assistance Publique-Hôpitaux de Paris, Paris, France; 8 1st Faculty of Medicine, Charles University and General University Hospital, Prague, Czech Republic; ${ }^{9}$ The Hospital for Sick Children, University of Toronto, Toronto, Canada; 10 Bicêtre University Hospital, , APHP, University of Paris Sud, Paris, France; ${ }^{11}$ Hospital for Children and Adolescents, University of Helsinki, Helsinki, Finland; ${ }^{12}$ Gaslini Children's Hospital, Genoa, Italy; ${ }^{13}$ Meir Medical Center, Kfar Saba, Tel Aviv University, Sackler School of Medicine, Tel Aviv, Israel; ${ }^{14}$ Institute of Translational Medicine, University of Liverpool, Liverpool, United Kingdom

* Joint first authors, contributed equally to this work

\section{Corresponding author:}

Professor Michael W Beresford

Institute in the Park, University of Liverpool

Alder Hey Children's NHS Foundation Trust

East Prescott Road,

Liverpool L14 5AB

m.w.beresford@liverpool.ac.uk

+441512824536

\section{Key messages}

1. Primary systemic vasculitides are rare and serious diseases of young, with little high-level evidence to guide management

2. Failure to recognise these diseases results in poor outcomes

3. Their rarity and lack of robust outcome measures has historically hampered the ability to perform clinical trials

4. Whilst awaiting results of the first trials, recommendations based on expert opinion and adult data for the investigation, diagnosis and treatment of systemic vasculitis of young are presented 


\section{Key words}

Childhood / paediatric; Systemic vasculitis; Polyarteritis Nodosa; Granulomatosis with Polyangiitis; Microscopic Polyangiitis; Eosinophilic Granulomatosis with Polyangiitis; Takayasu Arteritis; SHARE recommendations; Treatment

\section{Disclosure Statement}

None declared

\section{Funding Statement}

This work was supported by the European Agency for Health and Consumers (EAHC; grant number 2011 1202) 


\section{ABSTRACT \\ Background}

The European initiative SHARE (Single Hub and Access point for paediatric Rheumatology in Europe) aimed to optimize care for children with rheumatic diseases. Systemic vasculitides are very rare in children. Consequently, despite recent advances, paediatric-specific information is sparse. The lack of evidence-based recommendations is an important, unmet need.

\section{Objectives}

To provide recommendations for diagnosing and treating children with rare forms of childhood systemic vasculitis.

\section{Methods}

Recommendations were developed by a consensus process in accordance with the European League Against Rheumatism standard operating procedures. A systematic literature review informed the recommendations, which were devised and evaluated by a panel of experts via an online survey, and two consensus meetings using nominal group technique. Recommendations were accepted when $\geq$ $80 \%$ of experts agreed.

\section{Results}

Ninety-three relevant articles were found, and 78 recommendations were accepted in the two consensus meetings. General, cross-cutting recommendations and disease-specific statements regarding the diagnosis and treatment of childhood-onset Polyarteritis Nodosa, Granulomatosis with Polyangiitis, Microscopic Polyangiitis, Eosinophilic Granulomatosis with Polyangiitis, and Takayasu Arteritis are provided.

\section{Conclusions}

These SHARE recommendations were formulated through an evidence-based consensus process to support uniform, high-quality standard of care for children with rare forms of paediatric systemic vasculitis. 


\section{INTRODUCTION}

Rare forms of primary systemic vasculitis include: Polyarteritis Nodosa (PAN), Granulomatosis with Polyangiitis (GPA), Microscopic Polyangiitis (MPA), Eosinophilic Granulomatosis with Polyangiitis (EGPA), and Takayasu Arteritis (TA)(1, 2) (3). Clinical manifestations are highly variable, often multisystemic, and can impact markedly on growing children(4). Organ damage and mortality are associated, particularly if diagnosis and treatment are delayed. The incidence of systemic vasculitis amongst children is low, poorly characterized, and probably $<1 / 100,000$ for each individual disease(5).

Significant progress has been made through collaborative research networks to advance the care and understanding of disease management of patients with systemic vasculitides, particularly ANCAassociated vasculitides in adults (the reader is referred to the European vasculitis Society [EUVAS] website: http://www.vasculitis.org/). Key challenges facing paediatricians include major delays to clinical diagnosis and referral to centres with expertise in looking after children with these rare conditions, variability in access to medications and specific aspects of managing children within a multi-disciplinary team. The paediatric vasculitis research community has been proactive over recent years in developing classification criteria and outcome measures to facilitate the conduct of clinical trials designed to provide an evidence base for the treatment of childhood primary systemic vasculitides, and indeed 3 trials including children with primary systemic vasculitis are ongoing: MYCYC, exploring mycophenolate mofetil for children and adults with ANCA-associated vasculitis (EudraCT number: 2006-001663-33, manuscript submitted); MYPAN, exploring mycophenolate mofetil for children with PAN (EudraCT number: 2013004668-71, ongoing); and PEPRS, exploring rituximab for children with ANCA-associated vasculitis (EudraCT number: 2012-002062-13, ongoing). Whilst we await the results of those trials, evidencebased consensus recommendations aimed at improving diagnosis, management, and ultimately outcomes for children affected by these disorders are urgently required but are currently lacking due to the rarity of these diseases in childhood. Accordingly, current management of vasculitis of the young differs widely.

The European initiative SHARE (Single Hub and Access point for paediatric Rheumatology in Europe) aims to optimize care for children and young adults with Paediatric Rheumatic Diseases(6-11). For rare forms of childhood systemic vasculitis (PAN, ANCA-associated vasculitides (AAV), and TA), the objective was to design cross-cutting and disease-specific evidence-based recommendations for diagnosis and treatment. Recommendations for the diagnosis and management of Kawasaki Disease and IgA Vasculitis are described in separate manuscripts.

These consensus recommendations, whilst acknowledging the lack of specific paediatric evidence are aimed at setting a minimum standard of care for patients looked after in different centres of expertise across different countries. They are thus aimed at general paediatricians working in shared care with specialist teams, and at specialists with less experience with paediatric systemic vasculitis. 


\section{METHODS}

A panel of 16 paediatric rheumatologists, nephrologists and other vasculitis experts from across Europe were selected from partners of the SHARE consortium. All needed to be senior consultants with at least 10 years' experience working in a major tertiary paediatric rheumatology referral centre routinely looking after children with systemic vasculitides as part of a multi-disciplinary team. We used previously described SHARE methods(9) and the European League Against Rheumatism (EULAR) standardised operating procedures(12) for developing best practice recommendations.

\section{Systematic literature review}

Based on specific research questions identified a priori to focus on both cross cutting and disease specific matters pertaining to both diagnosis and management by the SHARE team (MWB, SK, NdG, NG, BV, NW, PB), the PubMed/MEDLINE, EMBASE and Cochrane databases were systematically searched on $20^{\text {th }}$ June 2013. All systemic vasculitides synonyms were searched using MeSH/Emtree terms using a validated filter pertaining to children and adolescents only (see Supplementary Table S1)(13). Articles were assessed using pre-specified inclusion/exclusion criteria (Table S2). All articles were screened independently by two reviewers (NdG, NG) and checked full text when necessary to determine eligibility. Disagreement was resolved by a third reviewer (MWB); agreement was reached in all cases. Additional key articles related to these childhood systemic vasculitides identified between the initial literature search and the final manuscript drafting (May 2017) were identified. Whilst these did not directly inform the recommendations, they were included in the manuscript commentary to provide upto-date face validity and contextualization.

\section{Validity assessment}

All papers were analysed by the expert panel (two reviewers per article) using standardised data extraction and predefined scoring forms for demographics, diagnostic(14) and therapeutic studies(15). Any discrepancies were resolved by a third expert (MWB) to reach consensus. Adapted tables for classification/diagnostic(16) and therapeutic(17) studies were used to determine the level of evidence and strength of each recommendation (Tables S3, S4).

\section{Establishing recommendations}

Provisional statements regarding diagnosis and treatment were developed using data from the included articles (NdG, NG, PB, SO, SK and MWB). Adult-derived literature was used to inform the development of the recommendations whenever it was available and when the level of evidence was insufficient from paediatric-specific data to inform the group. Provisional statements were presented to the expert committee $(n=14)$ in an online survey. Recommendations were revised according to responses $(100 \%$ response rate) and discussed at two face-to-face consensus expert meetings in January 2015 (Utrecht, $\mathrm{n}=10$ expert participants) and March 2015 (Barcelona, $\mathrm{n}=16$ ). Nominal group technique was used to reach consensus(18), with final recommendations accepted only with $\geq 80 \%$ agreement among experts. 


\section{RESULTS}

\section{Literature review}

The literature search yielded 8,077 articles (Figure S1). Articles on Kawasaki Disease (KD; $n=826$ ) and IgA Vasculitis ( $n=271$ ) were excluded (separate manuscripts in preparation). A total of 93 relevant articles meeting the search criteria remained (Table S5). These related to systemic PAN (excluding cutaneous PAN) ( $n=20)$; AAV ( $n=31)$ : GPA $(n=19)$, EGPA $(n=1)$, MPA $(n=1)$, and for various forms of systemic vasculitis $(n=10)$; TA $(n=38)$; and multiple forms of childhood systemic vasculitides $(n=4)$. Further key references identified in the interim from the initial literature search and the time of final manuscript drafting (July 2017) were also identified and included to provide up-to-date face validity and context. Seventy-eight recommendations were accepted at the two consensus meetings pertaining to general cross-cutting recommendations and disease-specific statements (Figure S1 and S2). Fifty-eight of these were based on expert panel consensus alone (i.e. level of evidence 4 , strength of evidence D; Tables 1-4).

\section{Diagnostic recommendations}

\section{Cross-cutting classification and diagnostic recommendations (Table 1)}

An initial set of recommendations (Table 1) focused on criteria warranting referral to a specialist for suspected vasculitis to help prevent diagnostic delay. A stepwise diagnostic approach is recommended, considering differential diagnoses and extent of organ involvement, including basic screening investigations recommended for all patients. Important differential diagnoses (infection, malignancy, non-inflammatory vasculopathies, and monogenic auto-inflammatory diseases) all require consideration. The paediatric vasculitis activity score (PVAS)(19) was recommended for tracking baseline disease activity, and follow-up. Organ damage was recognized as an important part of assessment at diagnosis and follow up. It was acknowledged that although the paediatric vasculitis damage index (PVDI) is used in clinical studies(20), it is not yet formally validated.

\section{Disease-specific classification and diagnostic recommendations}

Table 2 lists disease-specific diagnostic recommendations for rare paediatric systemic vasculitis that should be considered in addition to the general vasculitis workup.

\section{ANCA-associated vasculitis: GPA \& MPA (Table 2)}

For GPA, the panel noted that whilst the ACR and Ankara 2008-EULAR/PRINTO/PReS classification criteria can be helpful to define a patient as having GPA, classification criteria should not be used in isolation for diagnostic purposes, an important point which is relevant for all the vasculitis syndromes with described classification criteria. For classification purposes (e.g. for defining epidemiology or inclusion in clinical trials), there was strong consensus in favour of the EULAR/PRINTO/PReS criteria, particularly due to their greater sensitivity $(3,21)$. Whilst there are no specific classification criteria for paediatric MPA, the Chapel Hill nomenclature(22) provide a useful definition for clinical studies in children, but again cannot be used in isolation for diagnostic purposes. Although the pattern of organ involvement is variable, upper airway, ear, nose and throat, pulmonary and renal involvement are 
common in $\operatorname{GPA}(3,23,24)$. MPA often causes necrotizing pulmonary capillaritis as well as glomerulonephritis(25). Determining the patient's ANCA status is essential when considering the diagnosis of GPA or MPA $(23,26,27)$. ANCA determination by immunofluorescence (IF) alone may provide suboptimal sensitivity and specificity(28), enzyme-linked immunosorbent assay (ELISA), was recommended, usually combined with IF in line with adult experience(29-31). ANCA can be directed to different antigens, anti-proteinase-3 (PR3) is more often seen in GPA(23), and myeloperoxidase (MPO) is more often present in MPA and EGPA $(25,32)$. Current routine ANCA assays are not a reliable measure of disease activity(33). Whilst serial quantified ANCA testing might be predictive of flares of vasculitis in adults $(34,35)$, no such data are available for children.

Tissue biopsy (e.g. kidney (light and electron microscopy), lung, nasopharynx or sinuses) and associated immunohistochemistry were recommended as important to confirm the diagnosis of $A A V(23)$. It was recognized that obtaining biopsy material should not unduly delay treatment in cases with organ- or life-threatening disease. Different imaging modalities are recommended in the diagnostic work-up of AAV, depending on individual patient symptoms (Table 2). For GPA work-up, computed tomography (CT) or magnetic resonance imaging (MRI) scans of the sinuses can be helpful, although sinusitis may be less frequent in paediatric GPA, because of physiological and anatomical underdevelopment of sinuses in young children(24).

\section{Classification and Diagnosis of EGPA (Table 2)}

As with MPA, it was noted that there are no internationally agreed classification criteria for EGPA in children. Thus, the Chapel Hill 2012 nomenclature(22) provides a useful definition that can be used for paediatric clinical studies, but are not diagnostic criteria. Other eosinophilic diseases including parasitic infections, primary hypereosinophilia/hypereosinophilic syndromes, and eosinophilic leukaemia should be proactively excluded(36). EGPA nearly always involves the respiratory tract and lungs, causing symptoms including severe asthma and rhinitis(36, 37). Gastrointestinal, neurological, and cardiac involvement are common and important determinants of outcome(36-38). Cardiac screening using electrocardiography (ECG) and echocardiography should be performed in all patients. Eosinophilic myocarditis is a particularly severe complication of EGPA. Thus, in selected patients, myocardial biopsy is warranted(36).

\section{Classification and Diagnosis of PAN (Table 2)}

Whilst both the ACR and Ankara 2008-EULAR/PRINTO/PReS classification criteria are available for PAN, there was strong consensus favouring use of the EULAR/PRINTO/PReS criteria should be used to classify PAN, because these relate to the childhood disease specifically(3). PAN in children has an extensive differential diagnosis: it is particularly important to exclude monogenic vasculitides such as deficiency of adenosine deaminase type 2 (DADA2)(39) and other monogenic auto-inflammatory syndromes with vasculitis as a feature(40). ANCA is typically negative in PAN(41).

The importance of targeted tissue biopsy was emphasized in suspected cases. However, the patchy nature of the disease limits sensitivity. Deep (surgical) skin biopsy may be required (as opposed to punch biopsy) in PAN to increase diagnostic sensitivity. Percutaneous renal biopsy is not usually 
indicated in PAN as there is a risk of haemorrhage from renal aneurysms. Thus, diagnosis of renal involvement is not dependent upon histological confirmation(41, 42). Catheter digital subtraction arteriography (DSA) was recommended as an important imaging procedure for diagnosing PAN but should be performed only in centres with specific paediatric expertise(41-43). It should be noted that DSA may be normal in patients with systemic $\operatorname{PAN}(41,43)$ due to absence of changes early in the disease course, resolution of changes following corticosteroid treatment and/or failure to image the affected arterial bed(43).

Specific recommendations were made on other imaging modalities, noting their strengths and weaknesses $(44,45)(46)(47,48)$. Judicial use of catheter DSA of the brain(47) and brain and/or leptomeningeal biopsy should be considered in selected cases upon discussion with an expert centre $(49,50)$. Whilst vascular imaging is crucial, echocardiography and ECG aid detection of heart and coronary artery involvement in $\operatorname{PAN}(41,51)$.

\section{Classification and Diagnosis of TA (Table 2)}

For paediatric TA, whilst ACR and Ankara 2008-EULAR/PRINTO/PReS classification criteria are available, there was strong consensus favouring use of the paediatric specific EULAR/PRINTO/PReS criteria(3) to classify TA. Although typically elevated in the early stages of TA, it was noted that normal acute phase reactants do not exclude the diagnosis, and that in late-stage disease, they may not be elevated despite ongoing disease activity $(20,52,53)$. The importance of four-limb blood pressure assessment was emphasised, particularly since it is one of the classification criteria for paediatric TA(3). The importance and selective use of multiple imaging modalities in the stepwise assessment of TA in childhood was emphasised (Table 2)(20,54).

\section{Treatment}

\section{Cross-cutting treatment recommendations}

Table 3 summarises cross-cutting recommendations for treating the rare paediatric systemic vasculitides. Levels of evidence for children are poor, principally extrapolated from adult studies and/or based on small descriptive paediatric studies. With these caveats in mind, Figure 1 presents a standard therapeutic approach to severe systemic vasculitis therapy (excluding crescentic glomerulonephritis) and Figure 2 presents an approach for the treatment of crescentic glomerulonephritis/rapidly progressive glomerulonephritis agreed by all experts (100\% agreement; 4D). Overarching principles included a period of intense treatment (induction therapy) followed by a period of less intense maintenance therapy. In addition, approaches to be taken when disease is refractory to remission or there is a major relapse. A detailed description of how to define remission is beyond the scope of this manuscript, although in clinical trials is usually defined as paediatric vasculitis score (PVAS) score of $0 / 63$ on 2 separate occasions at least 1 month apart ${ }^{19}$, and usually also associated with adherence to a protocolised corticosteroid taper depending on the study.

Induction regimens typically include high dose corticosteroids, IV cyclophosphamide (CYC), and therapeutic plasma exchange(55). CYC may be complicated by toxicity. Hence, ongoing clinical trials 
are examining safer alternatives(56). Adult-derived evidence clearly demonstrates its benefit(40), and has demonstrated that IV pulsed CYC has a more favourable therapeutic index than daily oral CYC(57, 58). Limited paediatric evidence reports favourable outcomes for children treated with IV CYC for AAV, PAN, or TA $(20,23,41)$. MESNA was recommended to be co-administered with IV CYC(59). Sperm cryopreservation should be considered for all post-pubertal males prior to receiving CYC, although the complexity of achieving this in sick patients was acknowledged(60). There was insufficient evidence and lack of agreement amongst experts to recommend routine ovarian protection using triptorelin.

Recommended first-line maintenance options based on expert opinion, uncontrolled descriptive paediatric studies, and extrapolation from adult vasculitis studies, are azathioprine (AZA); methotrexate (MTX); and mycophenolate mofetil (MMF), in line with AAV guidelines in adults(61). Rituximab (RTX), as recently demonstrated in adults(62), might be an important maintenance therapy for children with AAV. Currently there is no published evidence to support its routine use as a maintenance agent for children with AAV. In patients with other types of rare paediatric systemic vasculitis, RTX can be considered for refractory cases, or patients who cannot tolerate other treatment regimens $(40,63)$.

Primary induction therapy might fail or disease might initially respond, but subsequently relapse. In this situation, it was recommended that next steps to consider would include increased dose of corticosteroids (oral or IV), and a change in disease-modifying agent are usually warranted, after excluding non-compliance. In some specific cases or disease sub-types, RTX or MMF may be helpful primary induction agents. Second or third line therapeutic agents for induction and/or maintenance could include: MMF, MTX, anti-TNF agents, RTX, or tocilizumab in refractory or relapsing cases. Intravenous immunoglobulin (IVIG) and/or plasma exchange could also be considered.

Maintenance treatment may be withdrawn slowly over at least 6 months if a patient has been in remission for at least 12 months whilst on maintenance therapy. The experts also acknowledged, however, that this may need to be longer (e.g. 24 months) for AAV, in line with more recent adult recommendations(64). No specific recommendations were made for the actual weaning dose regimens of corticosteroids or stopping disease modifying agents.

As well as immunomodulatory treatment, other important aspects of management were noted (all largely based on expert opinion: 4D), including use of antiplatelet agents to prevent thrombotic complications associated with systemic vasculitis in the young(65); antibiotic prophylaxis (specifically against Pneumocystis Jiroveci Pneumonia, PJP); osteoporosis prophylaxis; and gastric protection (e.g. with protein pump inhibitors, PPIs) in case of gastric pain. For incipient gangrene or other critically severe ischaemic complications, IV epoprostenol should be considered (under expert guidance), although it was acknowledged that there is limited published paediatric evidence in this context(66).

\section{Disease-specific recommendations for treating rare paediatric systemic vasculitides}

In addition to the over-arching approaches described above, specific treatment approaches are 
important when particular vasculitides are diagnosed (summarised in Table 4).

\section{Treatment of ANCA-associated vasculitis: GPA and MPA (Table 4)}

In view of the lack of robust evidence in children and the high level of evidence in adult studies for AAV, it was recommended that EULAR recommendations for managing adult-onset AAV (first published in 2009(67), updated in 2016(64)), should also be followed for children. An important caveat to this was the aforementioned use of RTX as a maintenance agent in children with AAV. As clinical trials/studies involving paediatric AAV patients are clearly warranted, the panel agreed that given the rarity of this disease in the paediatric population, including children in adult-focused trials may be acceptable depending on the trial design and therapeutic agent under consideration. One example of this is the MYCYC trial(56). Use of biological agents, including RTX as an alternative to, or to limit exposure to CYC was recommended for paediatric AAV patients with critical organ or life-threatening disease failing to respond to standard vasculitis therapy, or in patients with concerns exist regarding CYC toxicity. Specific attention was also given to considering the use of prophylactic co-trimoxazole, since in addition to preventing PJP, it might help prevent upper respiratory tract relapses in GPA(68).

\section{Treatment of EGPA (Table 4)}

There was no specific high-level evidence underpinning disease-specific recommendations for paediatric EGPA. Hence, recommendations were based on descriptive studies(36, 37) and/or expert opinion. Thus, the general treatment approach outlined in Figure 1 was considered appropriate.

\section{Treatment of PAN (Table 4)}

In view of limited paediatric data, and pending the results of the aforementioned MYPAN trial, treatment of PAN is recommended to follow principally adult-onset PAN recommendations(67), albeit with IVpulsed CYC rather than daily oral CYC (as suggested for adults) for reasons previously discussed. Biologic treatment for PAN may be indicated in patients who fail to respond to standard therapy or where concern exists regarding cumulative CYC dose; either TNF-alpha or IL-6 blockade or B-cell depleting agents could be considered(63). Recommendations were also made for the approach to cutaneous disease in the absence of severe systemic inflammation and other major organ involvement as well as for maintenance therapy.

\section{Treatment of TA (Table 4)}

Due to lack of robust evidence in children, EULAR recommendations for adult TA were recommended for paediatric TA patients(53). Specialist centres with experience in treating paediatric TA patients should always be involved. In the absence of a suitable biomarker or imaging modality that can help monitor therapy, disease status should be carefully and regularly monitored clinically, supported by various investigations including MRI/MRA where appropriate (see also Table 2). The panel noted the importance of accurate, appropriate and frequent blood pressure monitoring, and specifically the significant challenges of treating TA-associated systemic hypertension(69). Significant or subclinical cerebrovascular involvement must be considered carefully when managing systemic hypertension, 
especially as a precipitous drop in blood pressure may cause major CNS damage due to decreased perfusion, a general principle when treating renovascular hypertension of the young(70-72). Acknowledging that systemic hypertension may not resolve even with appropriate medical management, referral for endovascular and revascularization procedures must be considered early, under specific indications, preferably when the disease is quiescent, and in centres of expertise $(20,53$, 69). Specific induction treatment of TA in children includes CYC or MTX, combined with high dose glucocorticoid therapy $(20,53)$. The panel acknowledged reports of the use of TNF-blockade, anti-IL-6 therapy, and/or rituximab for severe disease(20, 53, 73-81). Maintenance agents can include MTX, AZA, or $\operatorname{MMF}(20,53)$. Other therapies, including anti-platelet therapy and/or full anticoagulation, might be indicated(20,74).

\section{Renal involvement in childhood vasculitis}

Historically, outcomes for adults with vasculitis have been heavily influenced by severe renal involvement which has resulted in a specific focus on treatment pathways for those with rapidly progressive glomerulonephritis, a situation which also applies to paediatric practice. Whilst there is considerable overlap between patients with vasculitis with or without crescentic nephritis, we provide pathways summarising an approach to the treatment of severe systemic vasculitis in children, with or without renal involvement (Figures 1 and 2). Two considerations are important in the context of crescentic nephritis: emphasis on the differential diagnosis (to include anti-GBM disease) and importance of plasma exchange.

\section{Discussion}

Seventy-eight cross-cutting and disease-specific evidence-informed recommendations for diagnosing and treating PAN, GPA, MPA, EGPA and TA, were agreed upon by the European-wide group of paediatric vasculitis experts. The childhood systemic vasculitides addressed are rare childhood diseases, with very poor levels of evidence to inform practice. For exactly these reasons, recommendations were developed and the experience of experts was shared, for paediatricians or physicians who rarely encounter these patients. These recommendations provide expert guidance, not fixed protocols; nor should they be used in place of direct expert input when available.

Several investigations span the differential diagnosis of systemic vasculitides in the young. Many tests are required for staging vasculitic organ involvement with controversies and pitfalls in their interpretation. We were, therefore, necessarily specific regarding certain laboratory investigations and imaging techniques needed. This should not be misunderstood as indicative of high levels of evidence in support of these specific recommendations, but rather as an approach agreed upon by international experts. We distinguished between 'required' tests (largely applicable to all patients), and 'potential' tests to be considered for individual patients in specific circumstances as part of the diagnostic process, to help clinicians prioritise the order of the step-wise investigative approach. 
Figures 1 and 2 summarise the treatment pathways recommended. This guidance may be tailored for individual patients at the discretion of clinicians and should not be used in place of expert input. The low levels of evidence offered for treatment of these diseases necessitates extrapolation from adult studies, with all the caveats around that approach. This highlights the need for multicentre, international studies in this area. The rarity of these diseases, restrictions relating to regulatory requirements for international studies, and lack of industry interest in paediatric systemic vasculitides are major barriers. That said, these barriers are not impossible to overcome as exemplified by the soon-to-be published MYCYC trial which compared cyclophosphamide versus mycophenolate mofetil in adults and children with ANCA vasculitis. Moreover, rare disease clinical trial designs such as Bayesian analyses have been employed in the ongoing MYPAN trial, comparing cyclophosphamide versus mycophenolate mofetil in childhood polyarteritis nodosa. Lastly, the PEPRS study (pediatric polyangitis rituximab study) is exploring the safety and efficacy of rituximab in children with ANCA vasculitis, albeit in the context of an uncontrolled, prospective open-label study.

In conclusion, these evidence-informed recommendations strive to advance care for children with rare forms of systemic vasculitis. For most of the recommendations, lack of robust scientific evidence emphasises the urgent need for more research on these diseases to improve outcomes.

\section{Acknowledgements}

We are very grateful to Dr. Despina Eleftheriou (Great Ormond Street Hospital for Children, London, United Kingdom) and Dr. Marinka Twilt (Alberta Children's Hospital, Calgary, Canada), both of whom helped score the articles as part of the initial literature review.

\section{Contributors}

NW and BV designed the SHARE initiative. NdG and NG performed the systematic literature review, supervised by MWB and SK. Validity assessment of selected papers was done by SO, PB, LM, PD, AvR, DE and MT. Recommendations were formulated by NdG, NG, PB, SK and MWB. The expert committee consisted of PB, SO, TA, BB-M, PD, IK-P, PL, SDM, LM, CP, AvR, YU, NW, SK and MWB; they completed the online surveys and/or participated in the subsequent consensus meetings. NdG, NG, SK and MWB prepared, and NdG and NG chaired the consensus meetings and took minutes. AR and $\mathrm{BF}$ facilitated the consensus procedure using nominal group technique. MWB and PB wrote the manuscript, with contribution and approval of all co-authors. MWB oversaw all aspects as senior author, writing the original manuscript, editing and re-editing all and multiple revisions and alterations. 


\section{References}

1. Eleftheriou D, Batu ED, Ozen S, Brogan PA. Vasculitis in children. Nephrology, dialysis, transplantation : official publication of the European Dialysis and Transplant Association - European Renal Association. 2015;30 Suppl 1:i94-103.

2. Ozen S, Ruperto N, Dillon MJ, Bagga A, Barron K, Davin JC, et al. EULAR/PReS endorsed consensus criteria for the classification of childhood vasculitides. Ann Rheum Dis. 2006;65(7):936-41.

3. Ozen S, Pistorio A, lusan SM, Bakkaloglu A, Herlin T, Brik R, et al. EULAR/PRINTO/PRES criteria for Henoch-Schonlein purpura, childhood polyarteritis nodosa, childhood Wegener granulomatosis and childhood Takayasu arteritis: Ankara 2008. Part II: Final classification criteria. Ann Rheum Dis. 2010;69(5):798-806.

4. Dillon MJ. Childhood vasculitis. Lupus. 1998;7(4):259-65.

5. Gardner-Medwin JM, Dolezalova P, Cummins C, Southwood TR. Incidence of HenochSchonlein purpura, Kawasaki disease, and rare vasculitides in children of different ethnic origins. Lancet. 2002;360(9341):1197-202.

6. Wulffraat NM, Vastert B. Time to share. Pediatr Rheumatol Online J. 2013;11(1):5.

7. Giancane G, Ter Haar NM, Wulffraat N, Vastert SJ, Barron K, Hentgen V, et al. Evidence-based recommendations for genetic diagnosis of familial Mediterranean fever. Ann Rheum Dis. 2015;74(4):635-41.

8. Groot N, de Graeff N, Avcin T, Bader-Meunier B, Dolezalova P, Feldman B, et al. European evidence-based recommendations for diagnosis and treatment of paediatric antiphospholipid syndrome: the SHARE initiative. Ann Rheum Dis. 2017;76(10):1637-41.

9. Groot N, Graeff N, Avcin T, Bader-Meunier B, Brogan P, Dolezalova P, et al. European evidence-based recommendations for diagnosis and treatment of childhood-onset systemic lupus erythematosus: the SHARE initiative. Ann Rheum Dis. 2017.

10. ter Haar NM, Oswald M, Jeyaratnam J, Anton J, Barron KS, Brogan PA, et al. Recommendations for the management of autoinflammatory diseases. Ann Rheum Dis. 2015;74(9):1636-44.

11. Enders FB, Bader-Meunier B, Baildam E, Constantin T, Dolezalova P, Feldman BM, et al. Consensus-based recommendations for the management of juvenile dermatomyositis. Ann Rheum Dis. 2016.

12. Dougados M, Betteridge N, Burmester GR, Euller-Ziegler L, Guillemin F, Hirvonen J, et al. EULAR standardised operating procedures for the elaboration, evaluation, dissemination, and implementation of recommendations endorsed by the EULAR standing committees. Ann Rheum Dis. 2004;63(9):1172-6.

13. Leclercq E, Leeflang MM, van Dalen EC, Kremer LC. Validation of search filters for identifying pediatric studies in PubMed. The Journal of pediatrics. 2013;162(3):629-34.e2.

14. Whiting P, Rutjes AW, Dinnes J, Reitsma J, Bossuyt PM, Kleijnen J. Development and validation of methods for assessing the quality of diagnostic accuracy studies. Health technology assessment (Winchester, England). 2004;8(25):iii, 1-234.

15. Higgins JPT GSe. Cochrane Handbook for Systematic Reviews of Interventions. 2015. 
16. Zhang W, Doherty M, Pascual E, Bardin T, Barskova V, Conaghan P, et al. EULAR evidence based recommendations for gout. Part I: Diagnosis. Report of a task force of the Standing Committee for International Clinical Studies Including Therapeutics (ESCISIT). Ann Rheum Dis. 2006;65(10):130111.

17. Zhang W, Doherty M, Bardin T, Pascual E, Barskova V, Conaghan P, et al. EULAR evidence based recommendations for gout. Part II: Management. Report of a task force of the EULAR Standing Committee for International Clinical Studies Including Therapeutics (ESCISIT). Ann Rheum Dis. 2006;65(10):1312-24.

18. Harvey N, Holmes CA. Nominal group technique: an effective method for obtaining group consensus. International journal of nursing practice. 2012;18(2):188-94.

19. Dolezalova P, Price-Kuehne FE, Ozen S, Benseler SM, Cabral DA, Anton J, et al. Disease activity assessment in childhood vasculitis: development and preliminary validation of the Paediatric Vasculitis Activity Score (PVAS). Ann Rheum Dis. 2013;72(10):1628-33.

20. Eleftheriou D, Varnier G, Dolezalova P, McMahon AM, Al-Obaidi M, Brogan PA. Takayasu arteritis in childhood: retrospective experience from a tertiary referral centre in the United Kingdom. Arthritis Res Ther. 2015;17:36.

21. Cabral DA, Uribe AG, Benseler S, O'Neil KM, Hashkes PJ, Higgins G, et al. Classification, presentation, and initial treatment of Wegener's granulomatosis in childhood. Arthritis Rheum. 2009;60(11):3413-24.

22. Jennette JC, Falk RJ, Bacon PA, Basu N, Cid MC, Ferrario F, et al. 2012 revised International Chapel Hill Consensus Conference Nomenclature of Vasculitides. Arthritis Rheum. 2013;65(1):1-11.

23. Akikusa JD, Schneider R, Harvey EA, Hebert D, Thorner PS, Laxer RM, et al. Clinical features and outcome of pediatric Wegener's granulomatosis. Arthritis Rheum. 2007;57(5):837-44.

24. Belostotsky VM, Shah V, Dillon MJ. Clinical features in 17 paediatric patients with Wegener granulomatosis. Pediatr Nephrol. 2002;17(9):754-61.

25. Sacri AS, Chambaraud T, Ranchin B, Florkin B, See H, Decramer S, et al. Clinical characteristics and outcomes of childhood-onset ANCA-associated vasculitis: a French nationwide study. Nephrology, dialysis, transplantation : official publication of the European Dialysis and Transplant Association - European Renal Association. 2015;30 Suppl 1:i104-12.

26. Wong SN, Shah V, Dillon MJ. Anti-neutrophil cytoplasmic antibodies in childhood systemic lupus erythematosus. European journal of pediatrics. 1995;154(1):43-5.

27. Bohm M, Gonzalez Fernandez MI, Ozen S, Pistorio A, Dolezalova P, Brogan P, et al. Clinical features of childhood granulomatosis with polyangiitis (wegener's granulomatosis). Pediatric Rheumatology. 2014;12(1):18.

28. Wong SN, Shah V, Dillon MJ. Antineutrophil cytoplasmic antibodies in Wegener's granulomatosis. Arch Dis Child. 1998;79(3):246-50.

29. Savige J, Gillis D, Benson E, Davies D, Esnault V, Falk RJ, et al. International Consensus Statement on Testing and Reporting of Antineutrophil Cytoplasmic Antibodies (ANCA). American journal of clinical pathology. 1999;111(4):507-13. 
30. Savige J, Dimech W, Fritzler M, Goeken J, Hagen EC, Jennette JC, et al. Addendum to the International Consensus Statement on testing and reporting of antineutrophil cytoplasmic antibodies. Quality control guidelines, comments, and recommendations for testing in other autoimmune diseases. American journal of clinical pathology. 2003;120(3):312-8.

31. Stone JH, Talor M, Stebbing J, Uhlfelder ML, Rose NR, Carson KA, et al. Test characteristics of immunofluorescence and ELISA tests in 856 consecutive patients with possible ANCA-associated conditions. Arthritis care and research : the official journal of the Arthritis Health Professions Association. 2000;13(6):424-34.

32. Ben Ameur S, Niaudet P, Baudouin V, Le Bourgeois M, Houdouin V, Delacourt C, et al. Lung manifestations in MPO-ANCA associated vasculitides in children. Pediatr Pulmonol. 2014;49(3):285-90. 33. Finkielman JD, Merkel PA, Schroeder D, Hoffman GS, Spiera R, St Clair EW, et al. Antiproteinase 3 antineutrophil cytoplasmic antibodies and disease activity in Wegener granulomatosis. Annals of internal medicine. 2007;147(9):611-9.

34. Fussner LA, Hummel AM, Schroeder DR, Silva F, Cartin-Ceba R, Snyder MR, et al. Factors Determining the Clinical Utility of Serial Measurements of Antineutrophil Cytoplasmic Antibodies Targeting Proteinase 3. Arthritis Rheumatol. 2016;68(7):1700-10.

35. Kemna MJ, Damoiseaux J, Austen J, Winkens B, Peters J, van Paassen P, et al. ANCA as a predictor of relapse: useful in patients with renal involvement but not in patients with nonrenal disease. Journal of the American Society of Nephrology : JASN. 2015;26(3):537-42.

36. Eleftheriou D, Gale H, Pilkington C, Fenton M, Sebire NJ, Brogan PA. Eosinophilic granulomatosis with polyangiitis in childhood: retrospective experience from a tertiary referral centre in the UK. Rheumatology (Oxford). 2016;55(7):1263-72.

37. Zwerina J, Eger G, Englbrecht M, Manger B, Schett G. Churg-Strauss syndrome in childhood: a systematic literature review and clinical comparison with adult patients. Seminars in arthritis and rheumatism. 2009;39(2):108-15.

38. Gendelman S, Zeft A, Spalding SJ. Childhood-onset eosinophilic granulomatosis with polyangiitis (formerly Churg-Strauss syndrome): a contemporary single-center cohort. The Journal of rheumatology. 2013;40(6):929-35.

39. Nanthapisal S, Murphy C, Omoyinmi E, Standing A, Hong Y, Gomes SM, et al. Monogenic polyarteritis nodosa caused by ADA2 Deficiency: the GOSH experience. Pediatric Rheumatology Online Journal. 2015;13(Suppl 1):P8-P.

40. Eleftheriou D, Brogan PA. Therapeutic advances in the treatment of vasculitis. Pediatr Rheumatol Online J. 2016;14(1):26.

41. Eleftheriou D, Dillon MJ, Tullus K, Marks SD, Pilkington CA, Roebuck DJ, et al. Systemic polyarteritis nodosa in the young: a single-center experience over thirty-two years. Arthritis Rheum. 2013;65(9):2476-85.

42. Albert DA, Silverstein MD, Paunicka K, Reddy G, Chang RW, Derus C. The diagnosis of polyarteritis nodosa. II. Empirical verification of a decision analysis model. Arthritis Rheum. 1988;31(9):1128-34. 
43. Brogan PA, Davies R, Gordon I, Dillon MJ. Renal angiography in children with polyarteritis nodosa. Pediatr Nephrol. 2002;17(4):277-83.

44. Ozcakar ZB, Fitoz S, Yildiz AE, Yalcinkaya F. Childhood polyarteritis nodosa: diagnosis with non-invasive imaging techniques. Clin Rheumatol. 2016.

45. Ozcakar ZB, Yalcinkaya F, Fitoz S, Yuksel S, Acar B, Caltik A, et al. Polyarteritis nodosa: successful diagnostic imaging utilizing pulsed and color Doppler ultrasonography and computed tomography angiography. European journal of pediatrics. 2006;165(2):120-3.

46. Basoglu T, Akpolat T, Canbaz F, Bernay I, Albayrak S, Kilic M, et al. Tc-99m DMSA renal scan in polyarteritis nodosa with bilateral intraparenchymal renal artery aneurysms. Clinical nuclear medicine. 1999;24(3):201-2.

47. Eleftheriou D, Cox T, Saunders D, Klein NJ, Brogan PA, Ganesan V. Investigation of childhood central nervous system vasculitis: magnetic resonance angiography versus catheter cerebral angiography. Developmental medicine and child neurology. 2010;52(9):863-7.

48. Aviv RI, Benseler SM, Silverman ED, Tyrrell PN, Deveber G, Tsang LM, et al. MR imaging and angiography of primary CNS vasculitis of childhood. AJNR American journal of neuroradiology. 2006;27(1):192-9.

49. Benseler SM, deVeber G, Hawkins C, Schneider R, Tyrrell PN, Aviv RI, et al. Angiographynegative primary central nervous system vasculitis in children: a newly recognized inflammatory central nervous system disease. Arthritis Rheum. 2005;52(7):2159-67.

50. Elbers J, Halliday W, Hawkins C, Hutchinson C, Benseler SM. Brain biopsy in children with primary small-vessel central nervous system vasculitis. Annals of neurology. 2010;68(5):602-10.

51. Gunal N, Kara N, Cakar N, Kocak H, Kahramanyol O, Cetinkaya E. Cardiac involvement in childhood polyarteritis nodosa. International journal of cardiology. 1997;60(3):257-62.

52. Direskeneli H, Aydin SZ, Merkel PA. Disease assessment in Takayasu's arteritis. Rheumatology (Oxford). 2013;52(10):1735-6.

53. Mukhtyar C, Guillevin L, Cid MC, Dasgupta B, de Groot K, Gross W, et al. EULAR recommendations for the management of large vessel vasculitis. Ann Rheum Dis. 2009;68(3):318-23.

54. Mavrogeni S, Dimitroulas T, Chatziioannou SN, Kitas G. The role of multimodality imaging in the evaluation of Takayasu arteritis. Seminars in arthritis and rheumatism. 2013;42(4):401-12.

55. Wright E, Dillon MJ, Tullus K. Childhood vasculitis and plasma exchange. European journal of pediatrics. 2007;166(2):145-51.

56. Hampson LV, Whitehead J, Eleftheriou D, Tudur-Smith C, Jones R, Jayne D, et al. Elicitation of expert prior opinion: application to the MYPAN trial in childhood polyarteritis nodosa. PLoS One. 2015;10(3):e0120981.

57. de Groot K, Harper L, Jayne DR, Flores Suarez LF, Gregorini G, Gross WL, et al. Pulse versus daily oral cyclophosphamide for induction of remission in antineutrophil cytoplasmic antibody-associated vasculitis: a randomized trial. Annals of internal medicine. 2009;150(10):670-80.

58. Harper L, Morgan MD, Walsh M, Hoglund P, Westman K, Flossmann O, et al. Pulse versus daily oral cyclophosphamide for induction of remission in ANCA-associated vasculitis: long-term followup. Ann Rheum Dis. 2012;71(6):955-60. 
59. Matz EL, Hsieh MH. Review of Advances in Uroprotective Agents for Cyclophosphamide- and Ifosfamide-induced Hemorrhagic Cystitis. Urology. 2016.

60. Gajjar R, Miller SD, Meyers KE, Ginsberg JP. Fertility preservation in patients receiving cyclophosphamide therapy for renal disease. Pediatr Nephrol. 2015;30(7):1099-106.

61. Ntatsaki E, Carruthers D, Chakravarty K, D'Cruz D, Harper L, Jayne D, et al. BSR and BHPR guideline for the management of adults with ANCA-associated vasculitis. Rheumatology (Oxford). 2014;53(12):2306-9.

62. Guillevin L, Pagnoux C, Karras A, Khouatra C, Aumaitre O, Cohen P, et al. Rituximab versus azathioprine for maintenance in ANCA-associated vasculitis. N Engl J Med. 2014;371(19):1771-80.

63. Eleftheriou D, Melo M, Marks SD, Tullus K, Sills J, Cleary G, et al. Biologic therapy in primary systemic vasculitis of the young. Rheumatology (Oxford). 2009;48(8):978-86.

64. Yates M, Watts RA, Bajema IM, Cid MC, Crestani B, Hauser T, et al. EULAR/ERA-EDTA recommendations for the management of ANCA-associated vasculitis. Ann Rheum Dis. 2016;75(9):1583-94.

65. Eleftheriou D, Hong Y, Klein NJ, Brogan PA. Thromboembolic disease in systemic vasculitis is associated with enhanced microparticle-mediated thrombin generation. Journal of thrombosis and haemostasis : JTH. 2011;9(9):1864-7.

66. Zulian F, Costantini C, Montesco MC, Schiavon F, Zacchello F. Successful treatment of gangrene in systemic necrotizing vasculitis with iloprost. British journal of rheumatology. 1998;37(2):228-30.

67. Mukhtyar C, Guillevin L, Cid MC, Dasgupta B, de Groot K, Gross W, et al. EULAR recommendations for the management of primary small and medium vessel vasculitis. Ann Rheum Dis. 2009;68(3):310-7.

68. Stegeman CA, Tervaert JW, de Jong PE, Kallenberg CG. Trimethoprim-sulfamethoxazole (cotrimoxazole) for the prevention of relapses of Wegener's granulomatosis. Dutch Co-Trimoxazole Wegener Study Group. N Engl J Med. 1996;335(1):16-20.

69. Ladapo TA, Gajjar P, McCulloch M, Scott C, Numanoglu A, Nourse P. Impact of revascularization on hypertension in children with Takayasu's arteritis-induced renal artery stenosis: a 21-year review. Pediatr Nephrol. 2015;30(8):1289-95.

70. Kari JA, Roebuck DJ, McLaren CA, Davis M, Dillon MJ, Hamilton G, et al. Angioplasty for renovascular hypertension in 78 children. Arch Dis Child. 2015;100(5):474-8.

71. Shroff R, Roebuck DJ, Gordon I, Davies R, Stephens S, Marks S, et al. Angioplasty for renovascular hypertension in children: 20-year experience. Pediatrics. 2006;118(1):268-75.

72. Stadermann MB, Montini G, Hamilton G, Roebuck DJ, McLaren CA, Dillon MJ, et al. Results of surgical treatment for renovascular hypertension in children: 30 year single centre experience. Nephrology, dialysis, transplantation : official publication of the European Dialysis and Transplant Association - European Renal Association. 2010;25(3):807-13.

73. Filocamo G, Buoncompagni A, Viola S, Loy A, Malattia C, Ravelli A, et al. Treatment of Takayasu's arteritis with tumor necrosis factor antagonists. The Journal of pediatrics. 2008;153(3):4324. 
74. Keser G, Direskeneli H, Aksu K. Management of Takayasu arteritis: a systematic review. Rheumatology (Oxford). 2014;53(5):793-801.

75. Seyahi E. Takayasu arteritis: an update. Current opinion in rheumatology. 2016.

76. Caltran E, Di Colo G, Ghigliotti G, Capecchi R, Catarsi E, Puxeddu I, et al. Two Takayasu arteritis patients successfully treated with rituximab. Clin Rheumatol. 2014;33(8):1183-4.

77. Clifford A, Hoffman GS. Recent advances in the medical management of Takayasu arteritis: an update on use of biologic therapies. Current opinion in rheumatology. 2014;26(1):7-15.

78. Walters HM, Aguiar CL, Macdermott EJ, Adams A, Barinstein L, Dayton JD, et al. Takayasu arteritis presenting in the context of active tuberculosis: a pediatric case. Journal of clinical rheumatology : practical reports on rheumatic \& musculoskeletal diseases. 2013;19(6):344-7.

79. Unizony S, Stone JH, Stone JR. New treatment strategies in large-vessel vasculitis. Current opinion in rheumatology. 2013;25(1):3-9.

80. Ernst D, Greer M, Stoll M, Meyer-Olson D, Schmidt RE, Witte T. Remission achieved in refractory advanced takayasu arteritis using rituximab. Case reports in rheumatology. 2012;2012:406963.

81. Hoyer BF, Mumtaz IM, Loddenkemper K, Bruns A, Sengler C, Hermann KG, et al. Takayasu arteritis is characterised by disturbances of $B$ cell homeostasis and responds to $B$ cell depletion therapy with rituximab. Ann Rheum Dis. 2012;71(1):75-9.

82. KDIGO. Clinical Practice Guidelines for Glomerulonephritis. Official Journal of the International Society of Nephrology - Kidney International Supplements. 2012;2(2). 


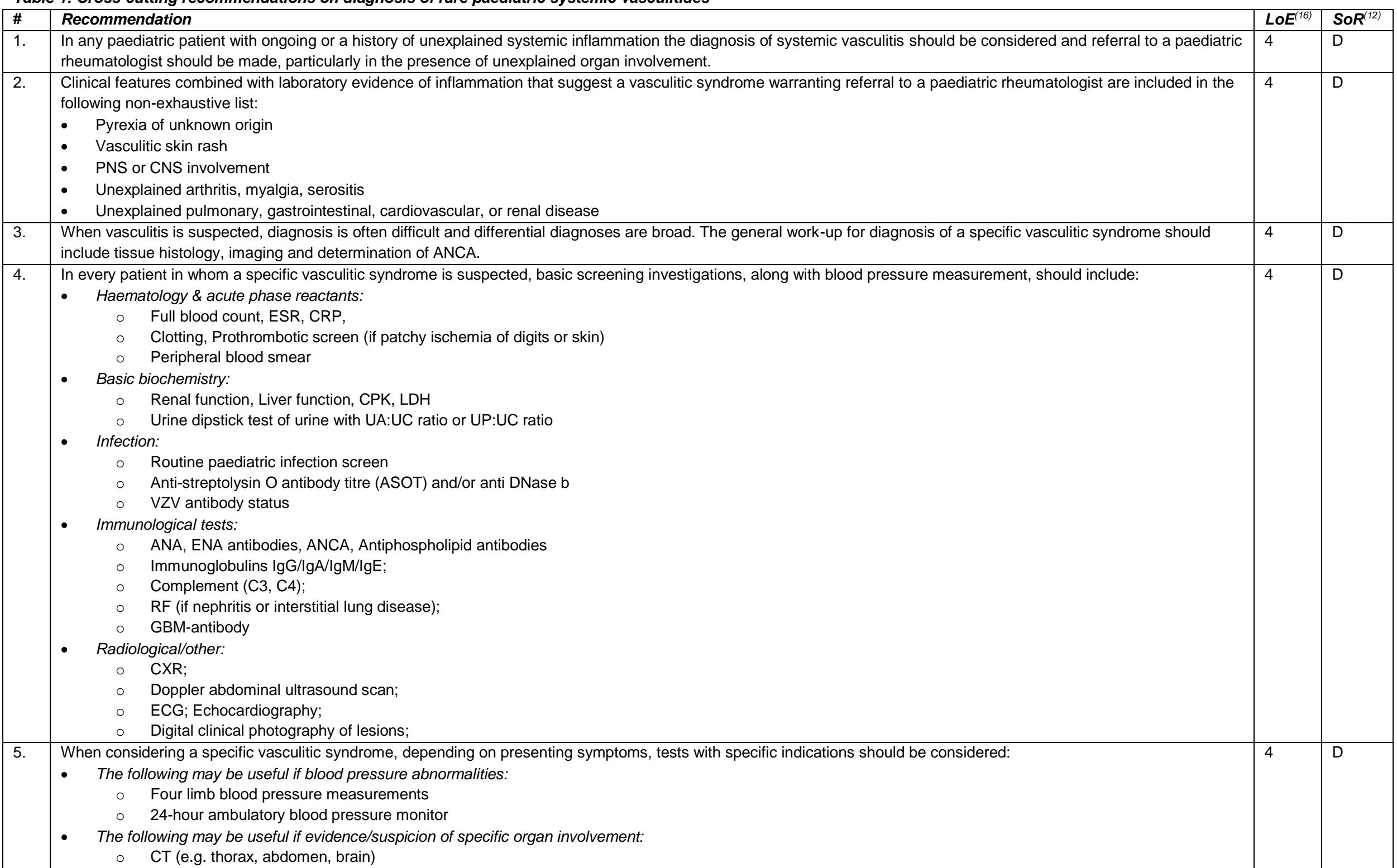




\begin{tabular}{|c|c|c|c|c|}
\hline & 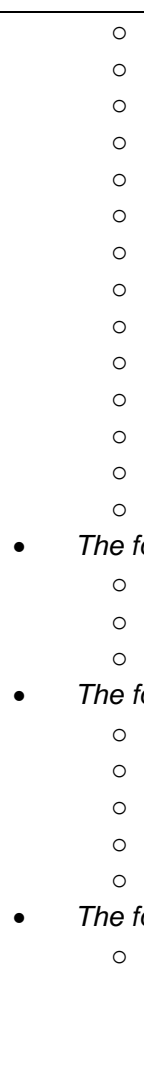 & $\begin{array}{l}\text { MRI } \\
\text { MRI/MRA of aorta and major branches } \\
\text { Selective contrast visceral arteriography } \\
\text { Tissue biopsy (e.g. skin, nasal or sinus, kidney, sural nerve, lung, liver, gut, temporal artery, brain) } \\
\text { Nail fold capillaroscopy } \\
\text { Possible bone/joint involvement: radiograph of suspected sites } \\
\text { Eye symptoms: ophthalmology screen } \\
\text { Pulmonary symptoms: V/Q scan } \\
\text { Renal involvement: Tc-99m DMSA scan } \\
\text { Peripheral vascular symptoms: Ultrasound scan Doppler of peripheral arteries } \\
\text { Neuropathy: nerve conduction studies } \\
\text { Cerebral involvement: MRI/MRA of brain and Cerebral contrast angiography } \\
\text { Organ specific auto-antibodies (e.g. ASCA's, brain/neuronal specific auto-antibodies) } \\
\text { Cryoglobulins or cryoprecipitants (technical expertise required), particularly if skin involved predominantly at peripheral sites } \\
\text { Ilowing may be useful when the differential diagnosis includes malignancy: } \\
\text { Lymph node excision biopsy } \\
\text { Bone marrow analysis } \\
\text { PET-CT } \\
\text { llowing may be useful when the differential diagnosis includes infection: } \\
\text { Tuberculosis screen } \\
\text { PCR for viral infection (e.g. CMV, EBV, enterovirus, Adenovirus, VZV, HBV, HCV) } \\
\text { Serology for HIV, Rickettsiae, Borrelia burgdorferi, Mycoplasma } \\
\text { Viral serology for Hepatitis B \& C, Parvovirus B19 } \\
\text { Cryoglobulins or cryoprecipitants (technical expertise required) } \\
\text { llowing may be useful when the differential diagnosis includes auto-inflammatory syndromes: } \\
\text { DNA analysis for MEFV (Familial Mediterranean Fever), TNFRSF1A (TNF alpha receptor associated periodic fever syndrome, TRAPS), MVK (mevalonate } \\
\text { kinase deficiency; previously referred to as Hyper IgD syndrome HIDS), NLRP3 (cryopyrin associated periodic syndrome, CAPS), NOD2 } \\
\text { (Crohn's/Blau's/juvenile sarcoid mutations), ADA2 (deficiency of ADA2), genetic screening for SAVI (TMEM173) and CANDLE (PSMB8, } 4 \text { and 9, and other } \\
\text { proteasome genes if available). }\end{array}$ & & \\
\hline 6. & In the clinic & al assessment of suspected systemic vasculitis, a structured multi-organ assessment should take place. & 4 & $\mathrm{D}$ \\
\hline 7. & $\begin{array}{l}\text { For suspec } \\
\text { http://ard.b }\end{array}$ & $\begin{array}{l}\text { ed systemic vasculitis, the paediatric vasculitis activity score (PVAS) may facilitate structured multi-organ assessment. The PVAS can be found here: } \\
\text { nj.com/content/72/10/1628.short }\end{array}$ & 3 & C \\
\hline 8. & At diagnos & and in ongoing-follow up of systemic vasculitis, a PVAS score should be performed to assess disease activity. & 4 & $\mathrm{D}$ \\
\hline 9. & At diagnos & and in ongoing follow-up of systemic vasculitis, a multi-organ assessment of damage should be undertaken. & 3 & $\mathrm{C}$ \\
\hline 10 . & $\begin{array}{l}\text { There is nc } \\
\text { can be ass }\end{array}$ & $\begin{array}{l}\text { urrently validated tool to assess paediatric vasculitis damage. This is an ongoing unmet need. The paediatric vasculitis damage index (pVDI), whilst un-validated, } \\
\text { ssed here: http://www.mypan.org.uk/Training.html }\end{array}$ & 4 & $\mathrm{D}$ \\
\hline
\end{tabular}


Abbreviations: PNS: peripheral nervous system; CNS: central nervous system; ANCA: antineutrophil cytoplasmic antibodies; ESR: erythrocyte sedimentation rate; CRP: C reactive protein; CPK: creatine phosphokinase; LDH: lactate dehydrogenase; UA:UC: urine albumin to urinary creatinine ratio; UP: UC; urine protein to urinary creatinine ratio; VZV: varicella zoster virus; ANA: antinuclear antibody; ENA: antibodies to extractable nuclear antigens; RF: rheumatoid factor; GBM: glomerular basement membrane; CXR: chest x-ray; ECG: electrocardiogram; CT: computer tomography; MRI: magnetic resonance imaging; MRA: magnetic resonance angiography; V/Q: ventilation/ perfusion; DMSA: dimercaptosuccinic acid; ASCA: Anti-Saccharomyces cerevisiae antibodies; PET: positron emission tomography; PCR: polymerase chain reaction; CMV: cytomegalovirus; EBV: Epstein-Barr virus; HBV: hepatitis $B$ virus; HCV: hepatitis $C$ virus; HIV: human immunodeficiency virus; DNA: Dexyribonucleic acid; TRAPS: TNF receptor associated periodic syndrome; ADA2: adenosine deaminase 2; SAVI: Sting associated vasculitis of infancy; CANDLE: chronic atypical neutrophilic dermatosis lipodystrophy and elevated temperature.

LoE, LoE, level of evidence: la = meta-analysis of cohort studies, Ib = meta-analysis of case-control studies; Ila = cohort studies, Illb = case-control studies, III = non-comparative descriptive studies; IV = expert opinion(16); SoR, strength of recommendation: $A$, based on level 1 evidence; $B$, based on level 2 or extrapolated from level 1; $C$, based on level 3 or extrapolated from level 1 or $2 ; D$, based on level 4 or extrapolated from level 3 or 4 expert opinion(12). 
\begin{tabular}{l|l}
1. & There are no validated diagnostic criteria for GPA or MPA
\end{tabular}

$2 . \quad$ There are 2 different classification criteria for GPA (Wegener's granulomatosis): the ACR criteria and the EULAR/PRINTO/PReS (Ankara 2008) criteria. The EULAR/PRINTO/PReS endorsed Ankara 2008 criteria should be used to classify GPA in the paediatric population.

3. No classification criteria exist for MPA; it is defined in the Chapel Hill (2012) nomenclature ${ }^{22}$. As no separate paediatric classification criteria exist, this definition should be used when referring to MPA for the purposes of epidemiological and/or clinical studies.

4. $\quad$ ANCA are important for the diagnosis of AAV.

5. It is essential to include ELISA (MPO and PR3) to detect ANCA; immunofluorescence alone is not sufficient for detection of ANCA.

6. $\quad$ ELISA (MPO and PR3) alone is more reliable for detection of ANCA than IF alone.

\begin{tabular}{lll}
\hline 7. & Current routine ANCA assays are an unreliable measure of disease activity and hence should not be used in isolation for disease monitoring purposes. \\
\hline 8. & His
\end{tabular}

8. Histopathological confirmation of the diagnosis of AAV is highly desirable but should not delay the start of treatment in patients with organ- or life-threatening disease.

\begin{tabular}{lll}
\hline 9. & Targeted tissue biopsy can be important for the diagnosis and staging of AAV
\end{tabular}

$\begin{array}{lll}10 . & \text { Immunohistochemistry (immunofluorescence) should be routinely undertaken in all biopsy specimens }\end{array}$

\begin{tabular}{l|l}
11. & Sinus imaging via CT or MRI may be helpful for the diagnosis of GPA.
\end{tabular}

12. A Chest X-Ray is indicated for all patients with AAV, followed up by chest CT in case of abnormal findings or if clinical concern of lung involvement remains despite a normal CXR

13. Pulmonary function tests should be performed, including Diffusing capacity / Transfer factor of the Lung for Carbon Monoxide (DLCO or TLCO) in patients with suspected lung involvement.

Eosinophilic Granulomatosis with Polyangiitis (EGPA)

$1 . \quad$ Since there are no paediatric diagnostic or classification criteria for EGPA (Churg Strauss), the Chapel Hill Definition (2012) should be used when referring to EGPA in the paediatric population.

2. The differential diagnoses of parasitic infection, primary hypereosinophilia/hypereosinophilic syndrome and eosinophilic leukaemia should be excluded in any paediatric patient where EGPA is suspected.

3. Eosinophilic myocarditis is an important and potentially fatal complication in EGPA. Careful assessment of the heart with echocardiography and ECG for this specific organ manifestation is warranted in all patients.

$4 . \quad$ Myocardial biopsy should be considered in selected patients.

\section{Polyarteritis Nodosa (PAN)}

$1 . \quad$ There are 2 different classification criteria for PAN: the ACR criteria and the EULAR/PRINTO/PReS endorsed Ankara 2008 criteria. - The EULAR/PRINTO/PReS Ankara 2008 criteria should be used to classify PAN in the paediatric population; see http://ard.bmj.com/content/69/5/798.full.pdf+html

2. The differential diagnosis of PAN requires consideration of inherited autoinflammatory syndromes such as ADA2 deficiency, SAVI and CANDLE syndrome.

\begin{tabular}{lll}
\hline 3. & ANCA are typically negative in PAN. \\
\hline
\end{tabular}

\begin{tabular}{lll}
\hline 4. & Targeted tissue biopsy should be performed in patients with suspected PAN. \\
\hline 5. & Due to the patchy nature of the dsease, absence of characterstic histopatholg
\end{tabular}

5. Due to the patchy nature of the disease, absence of characteristic histopathological changes on tissue biopsy does not exclude the diagnosis of PAN

\begin{tabular}{lll}
\hline 6. & Percutaneous renal biopsy is usually not indicated in PAN \\
\hline 7. & Catheter dital subtaction ateiography (DSA) is the mos
\end{tabular}

7. $\quad$ Catheter digital subtraction arteriography (DSA) is the most valuable imaging procedure for the diagnosis of PAN. DSA should be undertaken in centres with specific paediatric expertise for this test.

\begin{tabular}{lll}
\hline 8. & In early stages of disease or after treatment with corticosteroids arteriography may be normal; this does not exclude the diagnosis of PAN. \\
\hline
\end{tabular}

\begin{tabular}{|l|l|l}
\hline 4 & $\mathrm{D}$ \\
\hline $2 \mathrm{~A}$ & $\mathrm{C}$
\end{tabular}




\begin{tabular}{|c|c|c|c|c|}
\hline 9. & \multicolumn{2}{|c|}{$\begin{array}{l}\text { CT angiography may be useful for the diagnosis of PAN, but is less sensitive than DSA, and is associated with significant radiation exposure. Currently, MR angiography } \\
\text { lacks sensitivity for the diagnosis of PAN. }\end{array}$} & 4 & $\mathrm{D}$ \\
\hline 10. & \multicolumn{2}{|c|}{ In cases of suspected cerebral involvement, a cerebral MRI/MR angiography is indicated. } & 3 & $\mathrm{C}$ \\
\hline 11. & \multicolumn{2}{|c|}{$\begin{array}{l}\text { In cases of suspected cerebral involvement, catheter angiography of the brain may be considered in select cases as lesions, particularly those in the posterior circulation, } \\
\text { may be missed on MRA }\end{array}$} & 3 & $\mathrm{C}$ \\
\hline 12. & \multicolumn{2}{|c|}{ In cases of suspected cerebral involvement, brain and/or leptomeningeal biopsy may be considered in select cases, in discussion with an expert center. } & 4 & D \\
\hline 13. & \multicolumn{2}{|c|}{$\begin{array}{l}\text { Indirect evidence of the presence of medium-size artery vasculitis affecting renal arteries may be obtained by demonstrating patchy areas within the renal parenchyma of } \\
\text { decreased isotope uptake on Tc-99m dimercaptosuccinic acid (DMSA) scanning of the kidneys. }\end{array}$} & 4 & $\mathrm{D}$ \\
\hline 14. & \multicolumn{2}{|c|}{ ECG and Echocardiography can be useful for the identification of pericarditis, valve insufficiency, myocarditis, or coronary artery abnormalities. } & 3 & $\mathrm{C}$ \\
\hline \multicolumn{5}{|c|}{ Takayasu Arthritis (TA) } \\
\hline 1. & \multicolumn{2}{|c|}{$\begin{array}{l}\text { There are } 2 \text { different classification criteria for TA: the ACR criteria and the EULAR/ PRINTO/PReS-endorsed Ankara } 2008 \text { criteria. The EULAR/PRINTO/PReS (Ankara } \\
\text { 2008) criteria should be used to classify TA in the paediatric population; see http://ard.bmj.com/content/69/5/798.full.pdf+html }\end{array}$} & $2 \mathrm{~A}$ & C \\
\hline 2. & \multicolumn{2}{|c|}{ Acute phase reactants are typically elevated in the early stages of TA, but normal acute phase reactants do not exclude the diagnosis of TA. } & 3 & C \\
\hline 3. & \multicolumn{2}{|c|}{ In the later stages of disease, acute phase reactants may not be elevated, despite ongoing disease activity. } & 3 & $\mathrm{C}$ \\
\hline 4. & \multicolumn{2}{|c|}{$\begin{array}{l}\text { Other tests that may be required to exclude other causes mimicking TA, or for TA disease monitoring include: } \\
\text { - } \quad \text { Central blood pressure measurements (in case of significant peripheral artery stenosis) } \\
\text { - } \quad \text { Syphilis serology } \\
\text { - } \quad \text { Targeted arterial biopsy } \\
\text { - } \quad \text { Tuberculosis }\end{array}$} & 4 & $\mathrm{D}$ \\
\hline 5. & \multicolumn{2}{|c|}{ Four limb blood pressure should be performed regularly in all patients with TA. } & 4 & $\mathrm{D}$ \\
\hline 6. & \multicolumn{2}{|c|}{ Surveillance for end-organ damage should include formal ophthalmological assessment, echocardiography and ECG in all patients with TA } & 4 & D \\
\hline 7. & \multicolumn{2}{|c|}{$\begin{array}{l}\text { Imaging in TA requires a stepwise approach including multiple imaging techniques. An overview of relevant imaging techniques for imaging in TA with relevant } \\
\text { advantages and disadvantages is outlined below. }\end{array}$} & 4 & $\mathrm{D}$ \\
\hline \multicolumn{5}{|c|}{ su Arteritis - Vessel Imaging options } \\
\hline \multicolumn{2}{|c|}{ MRI/MRA and CTA } & \multicolumn{3}{|c|}{$\begin{array}{l}\text { MRA and CTA are of equal value for imaging of the vessel lumen, but MRA is preferable to CTA in children to minimise exposure to radiation. MRI/MRA also provides } \\
\text { information on arterial wall thickness, oedema and late gadolinium enhancement (the latter two usually being indicative of active disease). }\end{array}$} \\
\hline \multicolumn{2}{|c|}{ Doppler US } & \multicolumn{3}{|l|}{ Doppler USS is useful for imaging the carotids and renal arteries, but cannot cover deeper arteries and usually not the whole aorta. } \\
\hline \multicolumn{2}{|c|}{ PET-CT and PET-MRI } & \multicolumn{3}{|c|}{$\begin{array}{l}\text { PET-CT is useful for the detection of active large vessel vasculitis if positive, but a negative test does not exclude active disease definitively. This modality cannot be } \\
\text { routinely used for on-going monitoring of disease activity as the radiation dose is too high. PET-MRI is a newer development and is preferred when available. }\end{array}$} \\
\hline \multicolumn{2}{|c|}{$\begin{array}{l}\text { Digital subtraction arteriography } \\
\text { (catheter angiography) }\end{array}$} & \multicolumn{3}{|c|}{$\begin{array}{l}\text { Digital subtraction arteriography remains the gold standard for obtaining images of the vessel lumen. This imaging modality remains particularly important when } \\
\text { considering smaller vessels }(<5 \mathrm{~mm} \text {, including the coronaries) and for workup for revascularisation procedures such as angioplasty. }\end{array}$} \\
\hline \multicolumn{5}{|c|}{ Takayasu Arthritis - Additional imaging options } \\
\hline \multicolumn{2}{|c|}{ Heart and aortic imaging } & \multicolumn{3}{|c|}{$\begin{array}{l}\text { It is important to always evaluate the heart as well as the aorta and major branches (thoracic and abdominal) in TA, looking specifically for: aortic regurgitation, } \\
\text { ventricular hypertrophy secondary to hypertension, myocarditis and coronary involvement. Echocardiography should be the first line heart imaging technique, followed } \\
\text { by cardiac MRI (the latter being particularly good for detection of myocarditis). }\end{array}$} \\
\hline \multicolumn{2}{|c|}{ Cerebral imaging } & \multicolumn{3}{|l|}{ Consider brain imaging in all cases. Parenchymal changes on MRI may suggest ischaemia; cerebral MRA is important for identifying cerebral vasculitis. } \\
\hline
\end{tabular}


Abbreviations: AAV: ANCA associated vasculitis; ELISA: enzyme-linked immunosorbent assay; MPO: myeloperoxidase; PR3: proteinase 3; IF: immunofluorescence; PAN: polyarteritis nodosa;

$M R I=$ Magnetic Resonance Imaging; MRA = Magnetic Resonance Angiography; CTA = Computed Tomography Angiography; US = ultrasound; PET-CT = Positron emission tomography-computed tomography; PET-MRI = Positron emission tomography-Magnetic Resonance Imaging.

$L O E$, level of evidence: la = meta-analysis of cohort studies, $\mathrm{lb}=$ meta-analysis of case-control studies; $\mathrm{Ila}=$ cohort studies, $\mathrm{Ilb}=\mathrm{case}$-control studies, III $=$ non-comparative descriptive studies; $\mathrm{IV}=$ expert opinion (16); SoR, strength of recommendation: $A$, based on level 1 evidence; $B$, based on level 2 or extrapolated from level 1; $C$, based on level 3 or extrapolated from level 1 or 2; $D$, based on level 4 or extrapolated from level 3 or 4 expert opinion. (12) 
1. The treatment of severe systemic vasculitis (organ- or potentially life-threatening disease), requires a period of intense treatment (induction therapy) followed by a period of less intense maintenance therapy.

2. Whilst limited data prevent specific recommendations on induction therapy for vasculitic syndromes, a general approach for severe vasculitis may include treatment with Corticosteroids (methylprednisolone or prednisolone)

IV CYC

Therapeutic plasma exchange

3. IV CYC is preferred to oral CYC due to lower toxicity and comparable efficacy, as well as ensured adherence to treatment.

4. The following immunomodulatory agents should be considered for first-line maintenance:

$$
\text { AZA; MTX; MMF; Rituximab (for AAV) }
$$

5. Second or third line therapeutic agents for induction and/or maintenance that may be considered are: MMF, MTX, Rituximab, anti-TNF agents, IVIG, and/or Tocilizumab

6. $\quad$ In case of relapse or failed primary induction therapy, increased dose of corticosteroids (oral or IV) are usually warranted, and a change in disease modifying agent should be considered after exclusion of non-compliance.

7. There is no high-level evidence about how to stop maintenance therapy. However, treatment may be withdrawn slowly over at least 6 months if a patient has been in remission for at least 12 months on maintenance therapy

8. A general outline for treatment of severe systemic vasculitis is outlined in Figure 1. This outline can be followed for treatment of severe systemic vasculitis.

9. A general outline for treatment of crescentic glomerulonephritis/rapidly progressive glomerulonephritis is outlined in Figure 2 . This outline can be followed for treatment of crescentic glomerulonephritis/rapidly progressive glomerulonephritis.

10. During immunomodulatory treatment, other important aspects of management that should be considered are

- Antiplatelet agents

Antibiotic prophylaxis (specifically against PJP)

Osteoporosis prophylaxis

Gastric protection (PPI)

11. CYC should be administered with MESNA unless there is hypersensitivity to the latter

12. Sperm cryopreservation may be considered for all post-pubertal males prior to receiving CYC.

13. IV epoprostenol should be administered in case of incipient gangrene or other critically severe ischaemic complications.

\begin{tabular}{|l|l|}
\hline $\operatorname{LoE}^{(16)}$ & SoR $^{(12)}$ \\
\hline 4 & D \\
\hline 3 & C \\
& \\
\hline 3 & C \\
\hline 3 & C \\
\hline 3 & C \\
\hline 4 & D \\
\hline 4 & D \\
\hline 4 & D \\
\hline 4 & D \\
\hline 4 & D \\
\hline & \\
\hline 4 & D \\
\hline 4 & D \\
\hline
\end{tabular}

Abbreviations: IV: intravenous; AZA: azathioprine; CYC: cyclophosphamide; MTX: methotrexate; MMF: mycophenolate mofetil; IVIG: intravenous immunoglobulin: PJP: Pneumocystis Jiroveci Pneumonia; PPI: proton pump inhibitor; MESNA: 2-mercaptoethane sulfonate $\mathrm{Na}$ ( $\mathrm{Na}=$ sodium).

$L O E$, level of evidence: $1 A$, meta-analysis of randomised controlled trial; $1 B$, randomised controlled study; $2 A$, controlled study without randomisation; $2 B$, quasi-experimental study; 3 , descriptive study; 4 expert opinion(17); SoR, strength of recommendation: $A$, based on level 1 evidence; $B$, based on level 2 or extrapolated from level 1; $C$, based on level 3 or extrapolated from level 1 or 2;

$D$, based on level 4 or extrapolated from level 3 or 4 expert opinion.(12) 
Granulomatosis with Polyangiitis (GPA) \& Microscopic Polyangiitis (MPA)

$1 . \quad$ Considering the lack of evidence in children and the high level of evidence in adult studies for AAV, the EULAR recommendations on adult-onset AAV (2013) can be used in paediatric AAV patients.

2. $\quad$ Treatment with a biological agent may be indicated in AAV patients with critical organ or life-threatening disease which has failed to respond to standard vasculitis therapy, or in patients in whom concerns exist regarding CYC toxicity.

3. $\quad$ In case of treatment with a biological agent, B-cell depleting therapy should be the treatment of first choice

4. $\quad$ Cotrimoxazole is recommended to be added to treatment for AAV to help prevent bacterial infection, PJP, and to help prevent upper respiratory tract relapses in GPA.

5. $\quad$ Clinical trials/studies involving paediatric AAV patients are warranted; given the rarity of this disease in the paediatric population, inclusion of children in adult trials may

be acceptable depending on the trial design/therapeutic agent under consideration

Eosinophilic Granulomatosis with Polyangiitis (EGPA)

$1 . \quad$ No disease-specific recommendations have been noted for EGPA. For general treatment guidelines, see the section: "Cross-cutting recommendations on treatment of rare paediatric systemic vasculitides"

\section{Polyarteritis Nodosa (PAN)}

$1 . \quad$ Considering the lack of evidence in children, and the higher levels of evidence in adult studies on PAN, the treatment of severe PAN in children is based on published uncontrolled retrospective paediatric data, and recommendations for adult-onset PAN patients.

2. In patients presenting with cutaneous disease, in the absence of severe systemic inflammation and other major organ involvement, NSAID and/or corticosteroid treatment alone may be appropriate, with careful monitoring of clinical and laboratory parameters as this is weaned.

3. Treatment with a biological agent may be indicated in PAN patients that fail to respond to therapy with standard agents OR where concern exists regarding cumulative CYC dose.

4. $\quad$ Currently, no firm recommendation can be made regarding first choice of biological agent in PAN; TNF blockade, B-cell depleting therapy, or IL-6 blockade may be considered.

5. Following successful induction of remission, maintenance therapy should be administered for 12-36 months in PAN, depending on clinical course; some patients may require treatment for even longer.

Takayasu Arthritis (TA)

$1 . \quad$ Considering the lack of evidence in children and the higher level of evidence in adult studies on TA, the EULAR recommendations on adult-onset large vessel vasculitis (that relate to TA, not GCA) may be used in paediatric TA patients.

2. $\quad$ TA should be managed at an expert center because of the rarity of the disease, the limited availability of specialist imaging, specialist vascular surgery, and the difficulty associated with treating this condition (taken from adult guidelines).

$3 . \quad$ Monitoring of therapy should be clinical, supported by measurement of inflammatory markers and/or appropriate imaging

4. $\quad$ Follow-up imaging with MRI/MRA may assist assessment of disease activity.

5. $\quad$ Systemic hypertension is very frequent in paediatric TA. Blood pressure should be measured appropriately and interpreted using age, sex and height centile charts, and treated adequately.

6. Medical treatment of hypertension in TA may be challenging since renovascular hypertension may not respond to medical therapy alone; specialist advice from a paediatric nephrologist should be sought in treating TA hypertension.

7. It is essential to consider significant or subclinical cerebrovascular involvement in the management of systemic hypertension. A precipitous drop in blood pressure can cause major CNS damage due to decreased perfusion.

$8 . \quad$ If systemic hypertension does not respond to medical management, revascularization procedures may be required in TA.

9. Referral for consideration of surgical revascularization include:

- Hypertension from stenotic coarctation of the aorta or renovascular disease

\begin{tabular}{|l|l}
4 & D
\end{tabular}

D

\begin{tabular}{|l|l|}
\hline 4 & $D$ \\
\hline 4 & $D$ \\
\hline 3 & $C$ \\
\hline 4 & $D$ \\
\hline 4 & $D$ \\
\hline
\end{tabular}

\begin{tabular}{|l|l|l|}
\hline \multicolumn{2}{|l|}{} & \\
\hline & 4 & $D$ \\
\hline & 4 & $D$ \\
\hline & 4 & $D$ \\
\hline & 3 & C \\
\hline C & 4 & D \\
\hline & 4 & D \\
\hline & 4 & D \\
\hline 3 & C \\
\hline
\end{tabular}




\begin{tabular}{|c|c|c|c|}
\hline & $\begin{array}{ll}- & \text { End organ ischaemia or peripheral limb ischemia } \\
- & \text { Cerebral ischemia } \\
- & \text { Aortic or other arterial/cardiac aneurysms, or aortic regurgitation }\end{array}$ & & \\
\hline 10. & $\begin{array}{l}\text { Surgery during the acute phase of the disease carries significant risk of re-occlusion and procedural complication, so should be deferred until the acute phase is treated, } \\
\text { if possible. These techniques should only be undertaken in centers with expertise. }\end{array}$ & 4 & $\mathrm{D}$ \\
\hline 11. & CYC (for induction of remission) and/or MTX (for both induction and maintenance) plus corticosteroid therapy may help improve disease control. & 3 & C \\
\hline 12. & Maintenance agents for TA include MTX, AZA, and MMF. & 3 & C \\
\hline 13. & The use of TNF blockade, anti-IL-6 therapy (tocilizumab) or rituximab may be considered on a case-to-case basis; there are case reports of benefit. & 4 & D \\
\hline 14. & Anti-platelet therapy and/or full anticoagulation may be indicated. & 4 & D \\
\hline 15. & Clinical trials/studies involving paediatric TA patients are warranted & 4 & D \\
\hline
\end{tabular}

Abbreviations: EULAR: European league against rheumatism; NSAID: nonsteroidal anti-inflammatory drug; AZA: azathioprine; CYC: cyclophosphamide; MTX: methotrexate; MMF: mycophenolate mofetil; GCA: giant cell arteritis.

LoE, level of evidence: $1 A$, meta-analysis of randomised controlled trial; $1 B$, randomised controlled study; $2 A$, controlled study without randomisation; $2 B$, quasi-experimental study; 3 , descriptive study; 4 expert opinion(17); SoR, strength of recommendation: $A$, based on level 1 evidence; B, based on level 2 or extrapolated from level 1; $C$, based on level 3 or extrapolated from level 1 or 2; $D$, based on level 4 or extrapolated from level 3 or 4 expert opinion. (12) 
Figure 1: A standard therapeutic approach to severe systemic vasculitis therapy (based on consensus recommendations)

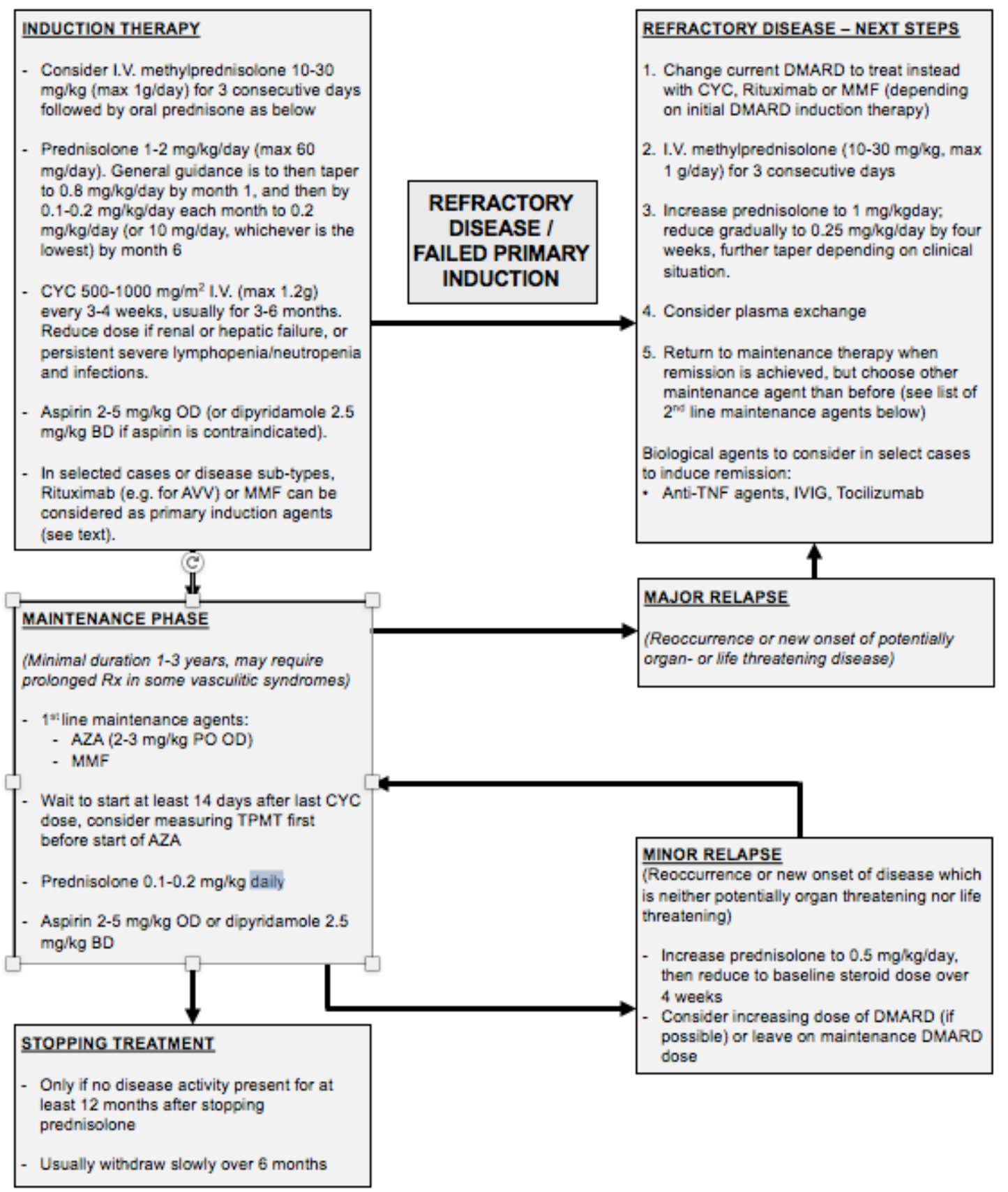

Figure 1: Second line maintenance agents include: MMF or AZA (if not used as first line maintenance treatment), MTX, Rituximab (for AAV - seek expert advice), and TNF blockade (seek expert advice). Other biological agents to consider in select individuals who fail to respond to standard induction therapy should be given under expert paediatric rheumatology or nephrology supervision only. Consider epoprostenol IV continuous infusion for incipient gangrene, seek expert advice regarding dose and duration. Abbreviations: AAV: ANCA Associated Vasculitides; BD: bi-daily; CYC: Cyclophosphamide; DMARD: Disease Modifying Anti Rheumatic Drug; IVIG: Intravenous Immunoglobulins; MMF: Mycophenolate Mofetil; MTX: Methotrexate; OD: Once daily; Rx: Treatment; TNF: Tumor Necrosis Factor; TPMT: thiopurine methyltransferase 
Figure 2: An approach for the treatment of crescentic glomerulonephritis/rapidly progressive glomerulonephritis (based on consensus recommendations)

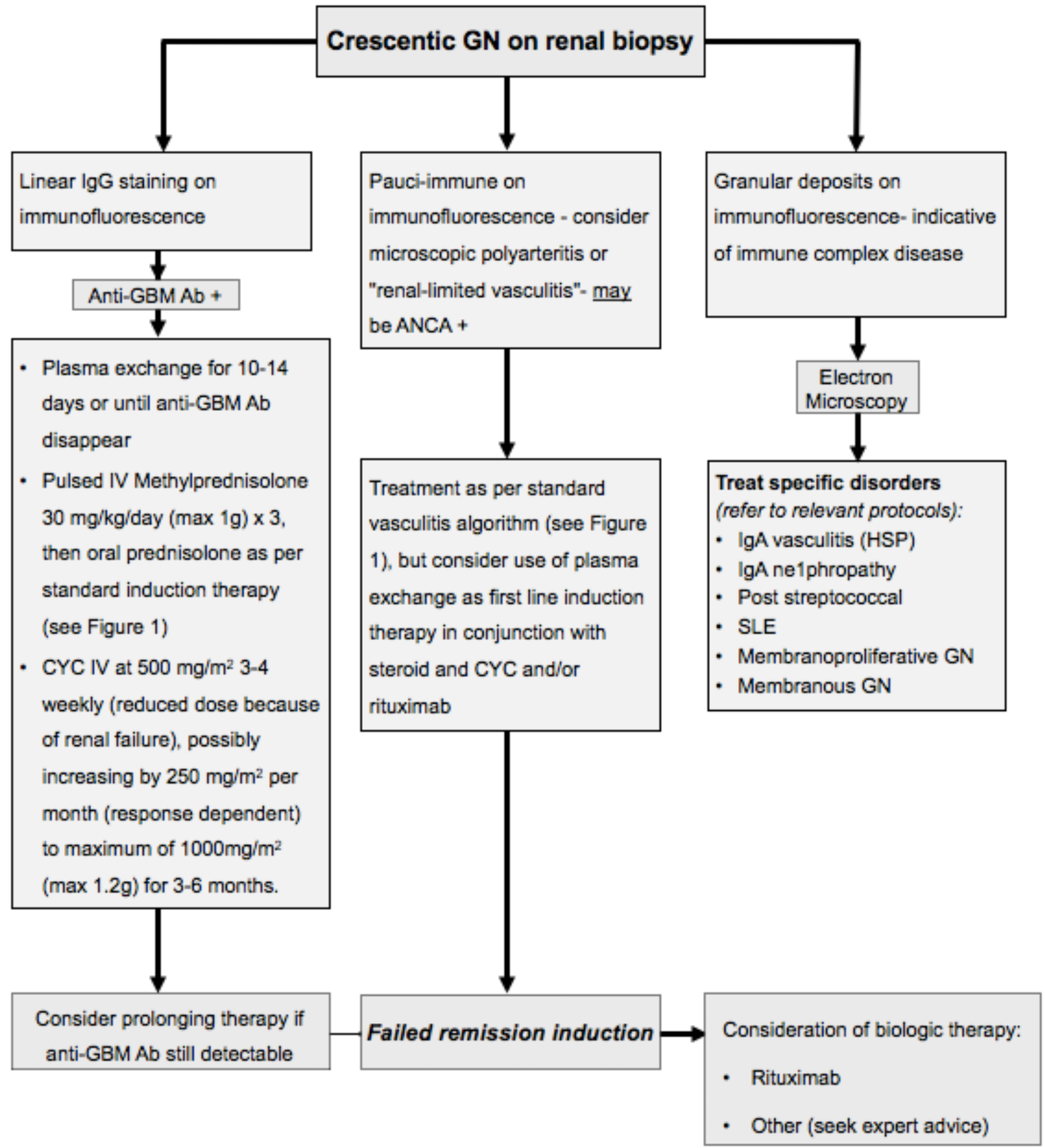

Figure 2: Guideline for treatment of crescentic glomerulonephritis. Of major importance is early diagnosis and prompt commencement of therapy to maximize chances of renal recovery. Management is always with expertise from paediatric nephrologists. Abbreviations: $\mathrm{GN}=$ glomerulonephritis; $\lg \mathrm{G}=$ Immunoglobulin G; Anti-GBM = Anti-glomerular basement membrane antibody; CYC = Cyclophosphamide; HSP = Henoch Schönlein Purpura; SLE = Systemic Lupus Erythematosus. 